\title{
INTERFACES DA HISTÓRIA DA ENFERMAGEM: A CONTRIBUIÇÃO DA ASSOCIAÇÃO BRASILEIRA DE ENFERMAGEM ${ }^{a}$
}

\author{
Nursing History Interfaces: \\ The Contribution of the Brazilian Nursing Association \\ Interfaces de la Historia de la Enfermería: \\ La contribución de la Asociación Brasileña de Enfermería
}

Isabel Cristina Kowal Olm Cunha

Maria Cristina Sanna

\begin{abstract}
Resumo
No contexto de transformação pela qual passou a Enfermagem brasileira, a Associação Brasileira de Enfermagem foi e é protagonista no cenário de compromisso com a categoria e a produção e difusão do conhecimento. A ABEn, como entidade representativa dos enfermeiros, liderou este processo, e neste artigo lança-se um olhar atento de avaliação do passado, entendendo o presente e, mais que tudo, desenhando as possibilidades para o futuro. Nessa perspectiva, 0 projeto de preservação do acervo e resgate da história da associação, em parceria com o NUPHEBRAS / EEAN, é um marco histórico que se reveste de importância para as próximas gerações de enfermeiros. Ao fazer o seu dever de conservar seu Centro de Documentação, disponibilizá-lo aos abenistas e às novas gerações, a ABEn reitera o seu compromisso com a história da Enfermagem brasileira, dando o exemplo que espera que frutifique.
\end{abstract}

Palavras-chave: História da Enfermagem. Sociedades de Enfermagem. Enfermagem.

\begin{abstract}
In the context of changes which Brazilian Nursing had passed, the Brazilian Nursing Association - ABEn, was and it is the protagonist in the scenery of commitment with the category and the production and dissemination of knowledge. The ABEn, as nurse's representative entity, leaded this process, and in this article, launches a look at with attention to evaluate the past, understanding the present and, more than everything, drawing possibilities for the future. In this perspective, the project of preservation of the pile and historical rescue of the association, in partnership with the NUPHEBRAS/EEAN, is a historical mark that is coated of relevance for the next generation of nurses. In comprising the duty of conserving its Documentation Center, and to make it available to ABEn's associates as well to the new generations, $A B E n$ reiterates its compromise with the history of Brazilian Nursing, giving an expected example.
\end{abstract}

Keywords:

History of Nursing. Societies, Nursing. Nursing.

\section{Resumen}

En el contexto de transformación por la cual pasó la Enfermería brasileña, la Asociación Brasileña de Enfermería era y es protagonista en el escenario de compromiso con la categoría y la producción y la difusión del conocimiento. La ABEn como entidad representativa de las enfermeras condujo este proceso y en este artículo, se lanza una mirada atenta de evaluación del pasado, entendiendo el presente y, más que todo, dibujando las posibilidades para el futuro. En esta perspectiva, el proyecto de preservación del acervo y el rescate de la historia de la asociación, en parcería con el NUPHEBRAS/EEAN, es un marco histórico que se recubre de importancia para las generaciones siguientes de enfermeros. Al hacer su deber de conservar su Centro de Documentación, hacerlo disponible a los asociados de la ABEn y a las nuevas generaciones, la ABEn reitera su compromiso con la historia de la Enfermería brasileña, dando el ejemplo esperado.

Palabras clave: Historia de la Enfermería. Sociedades de Enfermería. Enfermería. 


\section{CONTRIBUIÇÃO DA ABEn PARA A HISTÓRIA DA ENFERMAGEM}

A amplitude da temática que foi proposta força a refletir sobre como a história permeia todo objeto de estudo. De fato, seja qual for o tema em pauta, este carregará consigo uma história prévia, posto que não há identidade se não houver memória. Essa memória por sua vez permitirá 0 resgate de uma história particularmente percebida, que se compõe de dados objetivos, e principalmente da interpretação que se faz sobre eles. Isto significa que não é possível, apenas e tão somente, seguir relatando nomes, datas e acontecimentos, mas é preciso lançar um olhar atento sobre as circunstâncias em que estes ocorreram e as transformações destes resultantes, para que se possa situar o objeto de estudo e, aí sim, indagar sobre ele.

Os personagens da história, nessa perspectiva, são os atores que protagonizaram os fatos, vivenciaram o tempo e também aqueles que se debruçam sobre estes acontecimentos para revelá-los e compreendê-los. Dentre estes, se destaca a Associação Brasileira de Enfermagem, que foi e é protagonista no cenário de compromisso com a categoria, na qualidade de agente, e com a produção e difusão do conhecimento, na categoria de pesquisador, no contexto de transformações pelas quais passou a Enfermagem brasileira durante 0 século XX e neste início de século XXI.

0 estudo da história contribuiu para desenvolver a pesquisa em todos os campos e criou modos de entender o passado e novos métodos de pesquisar. A ABEn, como entidade representativa dos enfermeiros, liderou este processo. A maturidade desta jovem senhora de 80 anos bem vividos lança um olhar atento de avaliação do vivido, entendendo o presente e, mais que tudo, desenhando as possibilidades para o futuro. 0 Projeto ABEn 80 Anos proposto pela atual gestão pretende revisitar aspectos desta história .

É neste contexto que o projeto de preservação do acervo e resgate da História da Associação, feito em parceria com - NUPHEBRAS ${ }^{1}$, é um marco histórico que se reveste de importância para as próximas gerações de enfermeiros. Isto se dá porque não é possível congregar uma categoria profissional de diferentes gerações se não houver algo em comum - a própria história e, mais do que isso, a possibilidade de revê-la a todo e qualquer instante, num clima de liberdade para, tendo acesso a fontes primárias, continuamente revisitar esta mesma história.

A riqueza documental do acervo citado e as muitas interfaces de sua história constituem-se um conjunto de bens que, muito mais do que ser guardado como um tesouro, deve ir ao encontro das novas gerações de maneira organizada, a fim de poder colaborar com outros - e novos olhares.

Recentemente se observa um movimento de valorização da história, tímido ainda, que se esboça na criação e multiplicação de centros de memória das mais diversas atividades, que paulatinamente envolve a área da saúde. Apesar da existência de centros de referência consagrados como o do Departamento de Arquivo e Documentação da Casa de Oswaldo Cruz no Rio de Janeiro e o Museu de Saúde Pública Emílio Ribas de São Paulo, dentre outros, que são especíicos da área de saúde, há outros ainda por explorar, como o da Cúria Metropolitana do Rio de Janeiro, recentemente aberto, e outros consagrados e mais abrangentes como o da própria Biblioteca Nacional e os Arquivos Municipais, Estaduais e Nacional.

Trabalho recente que cataloga os acervos das Santas Casas de Misericórdia no país dão conta da pouca valorização que até recentemente fazia desaparecer preciosidades para dar lugar a "atividades mais úteis"2. Outro caso que chama à atenção é o da Maternidade São Paulo, que, a despeito dos apelos de historiadores renomados, permanece em risco ${ }^{3}$ e inacessível à pesquisa.

Num país que carece de centros de documentação, a Enfermagem tem seguido não preservando adequadamente a sua história, como apontaram Barreira e Baptista ${ }^{4}$ ao indicarem as limitações que a não-organização dos arquivos oferece para o desenvolvimento da pesquisa, e a importância da recuperação e preservação de fontes escritas, orais e iconográficas dos arquivos existentes e dos por serem criados, denominados "arquivos futuros".

Por estas tantas razões, o Centro de Estudos e Pesquisas de Enfermagem - CEPEn da ABEn Nacional e das Seções, deve ter papel relevante na mudança deste paradigma. Precisa, pois, ampliar seus limites, entendendo que a pesquisa conta e explica a história, e que, para entendê-la, é preciso usar métodos e fontes adequadas, através do fortalecimento de redes de comunicação em que a produção e a divulgação do conhecimento andem juntas.

Este projeto, que não é iniciativa pioneira, pois foi precedido de tentativa anterior ${ }^{5}$, não concretizada integralmente, de preparar a documentação para pesquisa, neste momento mais propício se apresenta como um dos principais empreendimentos na área de pesquisa em História da Enfermagem, capitaneados pela ABEn, que busca, com este gesto, fortalecer e fazer prosperar a idéia e a prática de fomentar a pesquisa e a divulgação de sua própria história e, por conseqüência, da História da Enfermagem.

Constituído por quatro subprojetos, num primeiro momento, procurar-se-á organizar e adequar o ambiente e providenciar o isolamento da sala de acervo com adequação das instalações físicas, para criação de condições ideais de preservação de documentos em relação à insolação, ventilação, umidade e proteção contra pragas, seguida de aquisição e montagem de equipamento específico de armazenamento e consulta.

0 segundo subprojeto tratará dos documentos textuais, para os quais providenciará higienização, estabilização e consolidação, acondicionamento conforme padrões técnicos recomendados pelos experts no assunto, inventário e criação de banco de dados com descrição dos itens arquivados, 
0 projeto com apoio do NUPHEBRAS ${ }^{1}$ já foi elaborado e recuperação digital dos documentos escritos e gravação de segurança em arquivo eletrônico, com possibilidade de abertura para consulta on-line. Registre-se que há cerca de 132 metros lineares de documentos que vão de 1926 a 2005.

0 terceiro subprojeto dirige-se aos documentos fotográficos para os quais se procederá às ações equivalentes aos documentos escritos, específicas para este material. Importante lembrar que este acervo abrange espaço temporal de 1925 a 2001, com aproximadamente 500 fotografias avulsas mais três álbuns.

0 quarto subprojeto diz respeito aos documentos fônicos, estes em menor quantidade, produzidos a partir de 1980, para os quais deverá ser feito um esforço adicional para recuperação de material retirado para pesquisa e ainda não devolvido, seguido de transcrição, edição, gravação eletrônica e elaboração de catálogo. É importante lembrar que isto é resultado de iniciativa do primeiro projeto de registro em história oral da ABEn Nacional, liderada pela Profa. Dra. leda de Alencar Barreira.

\section{Referências}

1. Escola de Enfermagem Anna Nery. Departamento de Enfermagem Fundamental. Núcleo de Pesquisa de História da Enfermagem Brasileira - NUPHEBRAS. Projeto de Preservação e Difusão do Acervo Documental da Associação Brasileira de Enfermagem. Rio de Janeiro(RJ); 2005. 7 p.

2. Khoury YA. Guia dos arquivos das Santas Casas de Misericórdia do Brasil fundadas entre 1500 e 1900. São Paulo(SP): Ed PUC; 2004.2 v.

3. Mott ML. Maternidade São Paulo pede socorro. [on-line] [citado 7 set 2005]. Disponível em: http://www.sogesp.com.br/jornal/ detalhes_jornal.asp?ed $=55 \&$ sun $=5$.

4. Barreira IA, Baptista SS. La investigación y la documentación em la historia de la enfermería em Brasil. Esc Anna Nery Rev Enferm 2000 dez; 4(3): 396-403.

5. Associação Brasileira de Enfermagem-ABEn.Centro de Estudos e Pesquisas de Enfermagem. Projeto de Restauro do Acervo. Brasília(BR); 1998. Mimeografado. orçado. Os primeiros contatos políticos para a formalização do pedido de financiamento já foram feitos, inclusive com a apresentação do projeto, e outros contatos já estão agendados. A instância deliberativa maior da entidade em reunião agendada para fim de outubro próximo deverá referendar este empreendimento considerado pela atual gestão como parte integrante do seu plano de trabalho.

Registre-se ainda que, desde 2002, a Revista Brasileira de Enfermagem, órgão oficial de divulgação científica da entidade, reserva espaço para apresentação de documentário e, há dois anos, com mais ênfase, ostenta uma sessão exclusiva para a publicação de resultados de pesquisa sobre História da Enfermagem. Mais recentemente, o Jornal da ABEn Nacional tem produzido e divulgado matérias jornalísticas específicas sobre história.

Ao fazer o seu dever de conservar seu Centro de Documentação, disponibilizá-lo aos abenistas e às novas gerações, a $A B E n$ reitera o seu compromisso com a história da Enfermagem brasileira, dando o exemplo que espera que frutifique.

\section{Nota}

${ }^{a}$ Apresentado em Mesa Redonda no II Colóquio Latino-Americano de História da Enfermagem, promovido pelo Núcleo de Pesquisa de História da Enfermagem Brasileira (NUPHEBRAS), em 2005.

\section{Sobre as Autoras}

\section{Isabel Cristina Kowal OIm Cunha}

Enfermeira. Doutora em Saúde Pública. Diretora de Publicação e Comunicação Social eEditora da Revista Brasileira de Enfermagem (REBEn) da Associação

\section{Maria Cristina Sanna}

Enfermeira. Doutora em Enfermagem. Pesquisadora independente. Líder do Centro de Estudos e Pesquisas sobre História da Enfermagem. Brasileira de Enfermagem (ABEn) Nacional Gestão 2004-2007. 